\title{
LOS VERBOS MODALES EN ESPAÑOL Y SUS EQUIVALENCIAS TRADUCTORAS EN POLACO: CASO DE DEBER
}

\author{
Monika Głowicka \\ Uniwersytet Wrocławski \\ http://dx.doi.org/10.18778/8220-201-4.09
}

\begin{abstract}
Resumen
El texto trata del verbo modal deber y sus equivalentes en polaco. El material de estudio lo constituye un corpus de usos de este verbo en las novelas españolas contemporáneas y las equivalencias en sus corespondientes traducciones al polaco. Se examinan cuestiones como la selección de lexemas en las traslaciones, existencia o no de algunas normas de traducción, el grado de equivalencia y los valores modales de los verbos en ambos idiomas.
\end{abstract}

Palabras clave: Verbos modales, equivalencias traductoras, deber, español - polaco.

\section{1.}

\section{Introducción}

Los verbos modales (por ejemplo, poder, deber) son lexemas que expresan obligación, habilidad, permiso, posibilidad, conjetura o certeza, entre otras cosas. Se estudian con profundidad en el marco de la lingüística inglesa y alemana, pero por no causar problemas en el aprendizaje de español o polaco no se les dedica tanta atención. No obstante, la problemática de la modalidad y de los 
verbos modales despierta el interés de los lingüistas polacos desde los años sesenta del siglo XX y en las últimas décadas se han publicado, por ejemplo, monografías sobre los equivalentes de los verbos modales franceses y polacos (Ligara, 1997), checos y polacos (Rytel, 1982) o búlgaros, entre otros (Korytkowska, 1977). Asimismo, en 2012 se publicó un estudio acerca de la expresión de la obligación en los códigos civiles polaco y español (Nowak-Michalska, 2012). En el presente artículo proponemos un análisis de carácter confrontativo, realizado a partir de las traducciones, del verbo modal deber.

\section{2.}

\section{Planteamientos metodológicos}

Nos hemos propuesto examinar dos estructuras, deber y deber de más infinitivo en los textos redactados en español y en sus traslaciones al polaco. Los estudios de carácter contrastivo suelen basarse en el cotejo de las gramáticas, de los manuales de idiomas para extranjeros, de los corpora disponibles o de las entradas en los diccionarios (en el caso de las unidades léxicas). En la última situación estamos ante lexemas descontextualizados, lo cual evidentemente limita su análisis. Nos planteamos el examen del verbo modal deber según el modo que puede denominarse el método comparativo de aproximación traductológica (en el marco de las relaciones entre la lingüística y la traductología; Kozłowska, 1985). Es un método realmente sencillo: se trata de un estudio unidireccional que consiste en la búsqueda de los usos de la unidad elegida (en nuestro caso del lexema deber) en los textos de partida que han de ser originales, homogéneos, por un lado (de la misma época, del mismo género) y heterogéneos, por otro lado (de varios autores, diferentes traductores), escritos sin fines metalingüísticos. Luego, se comparan con sus equivalentes en las traducciones a la lengua meta. Nuestro objetivo esencial es comprobar cuáles son los equivalentes léxicos en las traducciones al polaco del lexema deber, si se puede hablar de alguna norma en 
la traducción, si las traslaciones manifiestan el mismo tipo de modalidad; luego, nos interesa observar el funcionamiento de los modos y tiempos gramaticales y los valores semánticos en ambas versiones. Realizaremos nuestro análisis en el marco de traductología, gramática estructural y confrontativa.

\section{3.}

\section{Corpus de textos}

Para llevar a cabo la propuesta, hemos elegido seis novelas españolas contemporáneas y sus respectivas traducciones al polaco: la novela Tu rostro mañana de Javier Marías de 2002, traducida por Ewa Zaleska; El maestro de esgrima (1999) escrito por Arturo Pérez Reverte, con la traducción hecha por Filip Łobodziński (traductor de varias novelas de Pérez-Reverte). Otras novelas son de Eduardo Mendoza (Sin noticias de Gurb de 1991), traducida por Magdalena Tadel, La lluvia amarilla de Julio Llamazares (1989, traducción de Magdalena Płachta), La sombra del viento de Carlos Ruiz Zafón (2001, la traducción a cargo de Beata Fabjańska-Potapczuk y Carlos Marrodán Casas) y, finalmente, En ausencia de Blanca de Antonio Múñoz Molina (2001), traducida por Magdalena Potok-Nycz. De las seis novelas proviene un corpus constituido por 264 ejemplos que consideramos suficiente y representativo aunque no desprovisto de defectos (el análisis puede ofrecer resultados incompletos, son textos solo de género novelístico, sus traslaciones pueden verse afectadas por la subjetividad de los traductores, modas de traducción y otros factores). 


\section{4.}

\section{Verbos modales: su listado y características principales}

Como hemos señalado, el lexema deber pertenece al grupo de verbos modales que expresan, entre otras cosas, obligación, habilidad, permiso, posibilidad, conjetura o certeza. Se llaman modales (del lat. modus, modo) porque manifiestan la postura del hablante frente al enunciado. En su descripción se acude a los conceptos tradicionales del dictum (lo dicho, el contenido de la oración) y del modus (la actitud adoptada por el hablante respecto al contenido).

Lo pueden ilustrar los ejemplos:

- el dictum - Juanito llegará a tiempo.

- el modus - Juanito debe llegar a tiempo. Es probable que Juanito llegue a tiempo. ;Ojalá llegue a tiempo! (el contenido de la oración puede ser visto como necesario, probable o deseado).

El número de verbos modales no está bien determinado. Tradicionalmente incluía deber, poder, saber, querer, soler (Gili Gaya, 1994 [1943]: 119, las mismas ideas repetidas en el Esbozo de la $R A E$, 1983: 450). Por otro lado, hay verbos que pueden emplearse modalmente, es decir, pueden expresar alguna actitud del hablante. Gili Gaya (1994: 119) considera que la lista de los modales podría ser muy larga e incluir lexemas que designan intención, deseo, voluntad como mandar, desear, esperar, pensar o necesitar, mientras que Otaola Olano (1988: 112) afirma que "la modalidad es una categoría esencialmente semántica que se muestra plenamente en unos pocos verbos (poder, deber) y, en distinto grado, en otros muchos". En este momento no vamos a debatir sobre la lista de los llamados verbos modales. El verbo deber, al igual que poder, tener que o haber de, forma parte de las construcciones perifrásticas (dentro de las cuales funciona como verbo auxiliar) que se engloban bajo el nombre de perífrasis modales (Gómez Torrego, 1988: 30; García Fernández, Carrasco Gutiérrez, 2006: 110; NGLE, 2010: 2113).

En las investigaciones de los lingüistas polacos al grupo de los verbos modales suelen incluirse chcieć (querer), móc (poder), musieć (tener que), powinien (deber), woleć (preferir) (Gruszczyński, Bralczyk, 2002: 37-38), aunque la lista varía según los autores. 


\section{5.}

\section{Deber + infinitivo y sus traducciones}

Tradicionalmente, se afirma que el lexema deber, seguido de infinitivo, tiene el carácter obligativo (deóntico, de griego deón, obligación), mientras que deber de + infinitivo, el significado de probabilidad. Existe la tendencia de emplear deber + infinitivo en el sentido epistémico (conjetura, probabilidad) y mucho menos deber de + infinitivo con el valor deóntico de obligación, necesidad (García Fernández, Carrasco Gutiérrez, 2006: 111; NGLE, 2010: 2143). Tanto el valor de obligación como el de probabilidad derivan del valor esencial de necesidad. En la gramática de la Real Academia Española (RAE, 1983 [1973]: 448) se afirma que ya en la lengua clásica existía confusión entre ambas construcciones. Yllera (1980: 128-130) apunta que la estructura con la preposición de se empleaba ya en el siglo XVIII con el valor de necesidad y considera que la distinción moderna entre ambas perífrasis fue posterior y artificial. En los textos que hemos revisado, que son de carácter literario, deber + infinitivo denota obligatoriedad y, en ocasiones, se epistemiza, mientras que deber de manifiesta exclusivamente el valor epistémico (no recibe lectura deóntica).

En nuestro corpus de ejemplos en el cual descartamos el uso del lexema deber en el sentido de Le debo diez euros, la construcción con infinitivo aparece 187 veces. El equivalente más numeroso en las versiones polacas es el lexema powinien, con 76 ocurrencias, luego musieć con 39 casos.

\section{1 .}

\section{Traducción de deber a través de powinien}

En español deber es un verbo polisémico y ambiguo. Algo semejante ocurre con su correspondiente en la traducción, el lexema powinien (que tiene 76 equivalentes), que también resulta ambiguo. La construcción española con deber expresa:

- obligación clasificada como activa, usada con sujetos humanos agentes (Vosotros debéis trabajar más) 
- pasiva, con sujetos de cosa o sujetos humanos pacientes ( $E l$ salón debe tener más muebles, Gómez Torrego, 2000: 3349).

Según Gómez Manzano (1992: 163-165), la perífrasis con deber tiene valores de:

- obligatoriedad (conveniencia o necesidad)

- obligación impuesta por una actividad concreta, un quehacer

- obligación que el sujeto se impone a sí mismo

- obligación dictada por la costumbre o moral

- necesidad o conveniencia en el caso de un sujeto inanimado.

En nuestro corpus de ejemplos, la obligación activa queda reflejada en los siguientes ejemplos:

(1) Creo que debe cubrirse el rostro, señora de Otero (ME) $)^{1}$. Uważam, Pani de Otero, że powinna Pani zakryć sobie twarz (45).

(2) El maestro de esgrima había cavilado mucho sobre el recibimiento que debía dispensar a la dama... (ME)².

Fechmistrz długo rozmyślat tego dnia, w jaki sposób powinien podjąć damę... (42).

En ambos casos, el auxiliar denota una obligación derivada de una actividad concreta (práctica de esgrima, ejercicio de la profesión; el segundo ejemplo podría interpretarse también como obligación dictada por la costumbre). Es la obligación considerada débil o subjetiva (a diferencia de la expresada por tener que + infinitivo). El verbo modal polaco powinien manifiesta también el valor deóntico e implica la necesidad de realizar la acción impuesta, sea por el mismo hablante, sea por su interlocutor (y no tanto por circunstancias externas). Powinien se considera, al igual que su equivalente español, la manifestación de obligatoriedad de grado menos categórico que el verbo musieć (tener $q u e)$ aunque en la lingüística polaca no se opera con términos

1 Utilizamos las siguientes siglas: Tu rostro mañana - TR, El maestro de esgrima - ME, La sombra del viento - SV, Sin noticias de Gurb - SNG, La lluvia amarilla - LA, En ausencia de Blanca - AB.

2 En las versiones de novelas en papel ponemos los números de páginas; en las electrónicas, no se indican. 
obligación fuerte o débil. En polaco powinien puede recibir más de una lectura y denotar:

- obligatoriedad (Wszyscy powinni bronić sprawiedliwości - Todos deben defender la justicia)

- pertinencia, una acción que merece ser realizada por el sujeto (Powinieneś odwiedzić go - Deberías visitarlo)

- puede señalar algo posible (Klucze powinny być w torebce - Las llaves deben de estar en el bolso).

En los ejemplos citados estamos ante el segundo valor, de una acción que merece ser realizada. Powinien, además de designar la necesidad, contiene recomendación y consejo: en el caso de la no realización de una acción no hay sanciones, más bien un premio, la promesa de algo positivo.

En la perífrasis deber + infinitivo, de la idea de necesidad deóntica se desprende el valor desiderativo (García Fernández, Carrasco Gutiérrez, 2006: 110). Lo ilustra el caso:

(3) Debería usted echarle una mano [...] (TR: 119).

Powinien przyjść mu pan z pomoca (87).

En el original y su traducción, el valor de obligación (atenuada) está relacionado con el deseo del hablante de llevar a cabo una acción cuya realización es posible. Estamos ante una forma de cortesía.

En otros contextos, deber + infinitivo señala la obligación denominada pasiva (con sujetos de cosa, sujetos cero o humanos pacientes, distinción que no se hace en la lingüística polaca):

(4) Cuando hay asesinos de por medio... el asunto debe ser encarado por la autoridad competente... (ME).

Gdy mamy do czynienia z mordercami... sprawą powinny zająć się kompetentne organy... (146).

(5) Tal vez la invitación debería ir precedida de un obsequio (SN). Być może zaproszenie powinno być poprzedzone jakimś podarunkiem.

El verbo modal powinien expresa obligación, necesidad y probabilidad. Es un verbo defectivo que no tiene forma en infinitivo ni dispone de conjugación plena. Al igual que otros verbos 
modales carece de imperativo. Sus formas del tiempo presente se usan para hablar de las acciones situadas en pasado, presente o futuro. Como los verbos polacos tienen marcada la categoría de género, powinien tiene dos paradigmas de flexión y la forma impersonal powinno (Powinno padać-Debe/Debería llover).

Es un verbo que proviene de la forma predicativa del adjetivo powinny (como powinien jest, literalmente "él debido es") empleada en el siglo XV. Entre los siglos XV y XVII significaba "tiene obligación jurídica” y a partir del siglo XVIII iba ampliando su ámbito semántico. Fue entonces cuando empezó a funcionar como un pseudo-verbo powinienem, powinieneś (sin el lexema jest/es). El origen adjetival explica la peculiaridad formal de este verbo y su empleo indistinto en todos los tiempos gramaticales (Saloni, 1974: 95-96).

En la lingüística polaca en la tipología de verbos se distinguen verbos propios (flexivos) e impropios (no flexivos, impersonales). Powinien o se considera verbo propio atípico (no tiene infinitivo, participios, modo imperativo, tampoco dispone de todas las formas temporales; Saloni, 2012: 113-115) o, más frecuentemente, verbo impropio. En la clasificación sintáctica de las clases de palabras realizada por Laskowski (1981), es el llamado lexema predicativo (en polaco predykatyw), es decir, lexema que puede funcionar como verbo y que no tiene conjugación plena. En suma, powinien es el lexema que se describe como verbo no flexivo, defectivo, impropio, atípico y predicativo.

El verbo powinien, como ya hemos mencionado, se usa con relación a todas las perspectivas temporales. En las traducciones examinadas se dan empleos del tiempo pluscuamperfecto powinienem byt:

(6) Tal vez yo mismo debería haberle escrito esta mañana [...] $(L A)$.

Może powinienem był napisać do niego jeszcze dzisiaj rano [...] (120).

(7) [...] ordené que forzasen la puerta de la casa. Debíamos haberlo hecho mucho antes [...] (ME). [...] Powinniśmy byli to zrobić dużo wcześniej [...] (131). 
En polaco el pluscuamperfecto de indicativo ha caído en desuso y se sustituye actualmente por las formas del tiempo pasado (existe tan solo un tiempo verbal pasado). No obstante, se emplea todavía en el caso de la conjugación del lexema powinien, usado igualmente en las descripciones de los eventos pasados, presentes y futuros. Para evitar ambigüedades, se usan los exponentes del pluscuamperfecto. Fuera de los usos señalados, precisamente con el verbo powinien, el tiempo pluscuamperfecto prácticamente no se emplea.

En los originales citados, la perífrasis comentada se emplea en infinitivo compuesto: estamos ante un hecho que no se ha realizado y cuyo cumplimiento es irreal (valor contrafactivo). En polaco, las formas del pluscuamperfecto expresan el mismo valor de una acción no llevada al cabo e imposible de realizar.

Resumiendo, al examinar las traducciones al polaco se observa que deber y powinien tienen valores semejantes de obligación débil, interna, dictada por una actividad o la moral.

\section{2.}

\section{Traducción de deber a través de musieć}

En las traslaciones de las novelas al polaco, el verbo musieć aparece 39 veces. Por lo general, en las traducciones se mantienen los mismos tiempos y modos verbales:

(8) Debo recuperar la cabeza... (SNG: 15).

Muszę odzyskać głowę...

(9) Rolandi es un zurdo, nada más. Eso, que supone un riesgo para ti, es también una ventaja que debes aprovechar (ME). Rolandi jest mańkutem, ot wszystko. Owszem, stanowi to dla ciebie pewne ryzyko, ale też daje ci przewagę, z której musisz skorzystać (38).

Las oraciones en ambas versiones tienen el carácter deóntico, con la distinción entre la obligación impuesta por el interlocutor, expresada en el segundo caso y una orden que el hablante se dicta a sí mismo. En polaco, el verbo musieć expresa obligación externa. Está impuesta por una fuente de obligación (autoridad, ley) que es 
ajena, categórica e inevitable. Musieć, un verbo polisémico y ambiguo, puede denotar (según el diccionario $S J P D$ ):

1) estar sometido a alguna obligación, quedarse sin poder elegir;

2) considerar algo necesario, considerarlo como obligación (en nuestra opinión, es el valor expresado en los dos ejemplos citados supra);

3) querer algo con vehemencia;

4) ser probable, seguro (en este caso tiene valor epistémico).

En polaco, tanto musieć como powinien denotan obligatoriedad con diferentes matices. Powinien contiene recomendación, expresa pertinencia de hacer algo positivo a diferencia de musieć que puede señalar algún hecho valorado de manera negativa, pero que es inevitable. Así, se puede afirmar que una persona Musi kraść żeby przeżyć (Tiene que robar para sobrevivir), pero no vamos a recomendar Powinien kraść (Debe/debería robar).

En polaco el sentido de musieć puede explicarse mediante el análisis de los componentes señalados con acierto por Jędrzejko (1987: 37):

1) existe un $x$

2) $x$ tiene poder sobre $y$

3) $x$ quiere que $y$ haga $z$

4) si y no hace $z$, entonces $x$ hará $z^{1}$

5) $z^{1}$ es negativo para $y$

Mientras que, según comprueba Jędrzejko (1987), en polaco es una explicación válida para los usos de musieć con el valor deóntico, en las traducciones recopiladas tiene aplicación en escasos ejemplos:

(10) Digamos que están los que deben estar (ME). Powiedzmy, że są ci, którzy muszą na niej być (5).

(11) ...el que sabe tirar debe prever las intenciones del contrario... (ME).

...wytrawny szermierz musi przewidywać zamiary przeciwnika... (41).

La incompatibilidad del esquema con la mayoría de las unidades del corpus deriva, primero, del hecho de que en los textos los hablantes se imponen a sí mismos la obligación (no existe, por 
tanto, una fuerza externa, alguien que tenga poder sobre los sujetos) y, segundo, en otros casos, estamos ante usos epistémicos, de expresión de hipótesis:

(12) Bueno, ese debería ser el nombre, siendo viuda y siendo de York, yo creo. (TR: 121)

No cóż, myślę, że to musi być jej nazwisko, skoro jest wdowq iskoro jest z Yorku (88).

Las demás traducciones se hicieron a través del verbo mieć (tener) - 15 usos y la traducción libre (denominada también oblicua), es decir, mediante las omisiones de palabras o la llamada creación discursiva.

Las construcciones con powinien o musi no se clasifican en la lingüística polaca como perífrasis y se estudian de dos maneras diferentes: se consideran predicados verbales compuestos o predicados verbales simples en los que el verbo en infinitivo funciona como complemento (sobre la inexistencia de la categoría de perífrasis en polaco véase Zieliński, 2017: 179-237). En la gramática polaca entre los predicados verbales compuestos se distinguen predicados nominales, predicados con expresión fraseológica y predicados con el verbo auxiliar e infinitivo. Dentro del último grupo destaca el predicado modal. La estructura Muszę pracować (Tengo que/Debo trabajar) se trata como predicado compuesto modal, formado por el verbo auxiliar e infinitivo, pero el verbo muszę también puede analizarse como predicado verbal simple y pracować como su complemento (Gruszczyński, Bralczyk, 2002: 169).

\section{3.}

\section{Los equivalentes de la perífrasis deber de + infinitivo}

Dicha construcción aparece en las novelas analizadas 77 veces. Se asocia tradicionalmente con la expresión de una conjetura aunque, en la actualidad, se registran numerosos usos con el valor modal de necesidad. En las novelas revisadas el empleo de deber y deber de acompañados de infinitivo está delimitado y aunque en los trasvases al polaco de la perífrasis con deber de hay 
17 manifestaciones de lexemas musieć y powinien, estos expresan valores de probabilidad o certeza. En la mayoría de las traslaciones (33 veces) se emplean los adverbios modales: pewnie (probablemente, seguramente), zapewne (probablemente, ciertamente), najpewniej (con toda probabilidad, con toda seguridad).

(13) ... Juli, la novia de Mario, que llevaba siete años ya saliendo con él, debió de pensar que el amor infiel era una justificación más sólida o más prestigiosa que el tedio... (AB). ... Juli, dziewczyna Maria, uważała zapewne, że zdrada miłosna stanowi poważniejsze albo bardziej honorowe uzasadnienie porzucenia aniżeli nuda...

Tanto la perífrasis como el adverbio expresan la duda del hablante. En la lectura epistémica la necesidad se entiende como grado de certeza o probabilidad. A diferencia de la estructura sin preposición, en deber de con infinitivo no hay proyección futura. Los adverbios modales (modalizadores) funcionan como exponentes de hipótesis o aproximación. Las expresiones modales pewnie, najpewniej, zapewne tienen valores semánticos parecidos a las versiones originales:

(14) Debe de creer que estoy tratando de sacar tajada, pero me da igual (ME).

Najpewniej podejrzewa, że ciągnę z tego jakieś zyski, ale nie dbam o to (115).

(15) Debí de permanecer allí, paralizado, observándolos por espacio de casi medio minuto... (SV: 82).

Stałem tam pewnie z pót minuty, przyglądając im się... (66).

Pewnie supone que el hablante considera un hecho muy probable (Pewnie dobrze zarobię - Seguramente ganaré mucho). Zapewne encierra la suposición del hablante de que el juicio expresado es verdadero (Zapewne wiesz, co się stało - Seguramente sabes lo que ha pasado). Najpewniej supone certeza, implica algo que no despierta dudas. Las traducciones al polaco mediante estos adverbios revelan la elisión de los verbos (auxiliares y auxiliados), lo cual conduce a la transposición (cambio de clase de palabras) y a la reducción del enunciado. 


\section{6. \\ Observaciones finales}

Por lo que se refiere al nivel de equivalencia, debemos constatar que los homólogos polacos de las construcciones en la lengua de origen son de alto grado. En general, la obligatoriedad se expresa en ambas lenguas mediante los verbos modales y los adverbios modales. Las construcciones mantienen la misma estructura, el verbo conjugado más el infinitivo (con la ausencia del conector en polaco). En las traducciones se mantienen los mismos tiempos y modos, es decir, por lo general, el indicativo y los tiempos imperfectivos, el presente y el imperfecto. La perífrasis deber de se traslada mediante adverbios modales que denotan certeza o probabilidad. Lo que llama la atención es el hecho de que en más de 90 casos se han hecho traducciones libres, es decir, omisiones y modificaciones considerables del texto (las llamadas creaciones discursivas).

A nivel formal, en las gramáticas polacas no se distinguen las perífrasis verbales equivalentes a las construcciones en español. Existe el concepto de la perífrasis, pero se refiere a otro tipo de estructuras (predicados perifrásticos o formas analíticas de los tiempos verbales). Los equivalentes polacos de las perífrasis modales de obligación se aprecian como predicados verbales simples o compuestos (y no perífrasis).

\section{Referencias bibliográficas}

\section{Fuentes del corpus}

Llamazares, J. (1989), La lluvia amarilla, Barcelona: Seix Barral.

Llamazares, J. (2004), Żótty deszcz, trad. Magdalena Płachta, Warszawa: Warszawskie Wydawnictwo Literackie Muza S.A.

Marías, J. (2002), Tu rostro mañana. 1. Fiebre y lanza, Madrid: Alfaguara.

Marías, J. (2010), Twoja twarz jutro. Gorączka i włócznia, trad.

Ewa Zaleska, Katowice: Wydawnictwo Sonia Draga.

Mendoza, E. (2006 [1991]), Sin noticias de Gurb, Barcelona: Seix Barral. 
Mendoza, E. (2010), Brak wiadomości od Gurba, trad. Magdalena Tadel, Kraków: Wydawnictwo Znak.

Múñoz Molina, A. (2001), En ausencia de Blanca, Madrid: Alfaguara.

Múñoz Molina, A. (2003), Nieobecność Blanki, trad. Magdalena Potok-Nycz, Poznań: Dom Wydawniczy Rebis.

Pérez-Reverte, A. (1999), El maestro de esgrima, Madrid: Alfaguara.

Pérez-Reverte, A. (2002), Fechmistrz, trad. Filip Łobodziński, Warszawa: Warszawskie Wydawnictwo Literackie Muza SA.

Ruiz Zafón, C. (2010 [2001]), La Sombra del viento, Barcelona: Editorial Planeta S.A.

Ruiz Zafón, C. (2008), Cień Wiatru, trad. Beata Fabjańska-Potapczuk, Carlos Marrodán Casas, Warszawa: Warszawskie Wydawnictwo Literackie Muza SA.

\section{Obras de consulta}

García Fernández, L., Carrasco Gutiérrez, Á. (eds.) (2006), Diccionario de perífrasis verbales, Madrid: Gredos.

Gili Gaya, S. (1994 [1943]), Curso superior de sintaxis española, Barcelona: Bibliograf.

Gómez Manzano, P. (1992), Perífrasis verbales con infinitivo (valores y usos en la lengua hablada), Madrid: UNED.

Gómez Torrego, L. (1988), Perífrasis verbales. Sintaxis, semántica yestilística, Madrid: Arco Libros.

Gómez Torrego, L. (2000), "Los verbos auxiliares. Las perífrasis verbales de infinitivo", en I. Bosque, V. Demonte (eds.), Gramática descriptiva de la lengua española, Vol. 2, Madrid: Espasa Calpe, 3323-3390.

Gruszczyński, W., Bralczyk, J. (ed.) (2002), Słownik gramatyki języka polskiego, Warszawa: Wydawnictwa Szkolne i Pedagogiczne.

Jędrzejko, E. (1987), Semantyka i składnia polskich czasowników deontycznych, Wrocław: Zakład Narodowy im. Ossolińskich.

Korytkowska, M. (1977), Bułgarskie czasowniki modalne, Wrocław: Zakład Narodowy im. Ossolińskich. 
Kozłowska, Z. (1985), "Badania przekładowe a badania konfrontatywne”, en F. Grucza (ed.), Lingwistyka, glottodydaktyka, translatoryka: materiały $z$ VIII Sympozjum zorganizowanego przez Instytut Lingwistyki Stosowanej UW, Jadwisin, 5-7 listopada 1982, Warszawa: Wydawnictwa Uniwersytetu Warszawskiego, 239-252.

Laskowski, R. (1981), “Części mowy - problem syntaktyczny czy morfologiczny”, Folia Linguistica, 2, 117-131.

Ligara, B. (1997), Polskie czasowniki modalne i ich francuskie ekwiwalenty tlumaczeniowe, Kraków: Universitas.

Nowak-Michalska, J., (2012), Modalność deontyczna w języku prawnym na przykładzie polskiego i hiszpańskiego kodeksu cywilnego, Poznań: Wydawnictwo Rys.

Otaola Olano, C. (1988), "La modalidad (con especial referencia a la lengua española)", Revista de filología española, 68: 1/2, 97-117.

Real Academia Española (1983 [1973]), Esbozo de una nueva gramática de la lengua española, Madrid: Espasa-Calpe.

Real Academia Española (2010), Nueva gramática de la lengua española (NGLE), Madrid: Espasa Libros.

Rytel, D. (1982), Leksykalne środki wyrażania modalności w języku czeskim i polskim, Wrocław: Zakład Narodowy im. Ossolińskich.

Saloni, Z. (1974), "Klasyfikacja gramatyczna leksemów polskich”, Język Polski, LIV, 3-13, 93-101.

Saloni, Z. (2012), Stownikgramatyczny języka polskiego: podstawy teoretyczne, en Z. Saloni y M. Woliński, Słownik gramatyczny języka polskiego, Warszawa: Sowa.

(SJPD) Stownik języka polskiego, W. Doroszewski (ed.) [en línea] $<$ http://www.sjpd.pwn.pl/haslo/musiec87/>, [fecha de consulta: 29.01.2019].

Yllera, A. (1980), Sintaxis histórica del verbo español: las perífrasis medievales, Zaragoza: Departamento de Filología Francesa, Universidad de Zarazoga.

Zieliński A. (2017), "Perífrasis verbales", en W. Nowikow (ed.) Gramática contrastiva español-polaco, Łódź: Wydawnictwo Uniwersytetu Łódzkiego, 179-237. 